\title{
Benefit-Risk Assessment of Galcanezumab Versus Placebo for the Treatment of Episodic and Chronic Migraine Using the Metrics of Number Needed to Treat and Number Needed to Harm
}

Leslie Citrome $\cdot$ Margarita Sánchez del Rio · Yan Dong •

Russell M. Nichols · Antje Tockhorn-Heidenreich · Shonda A. Foster •

Virginia L. Stauffer

Received: April 30, 2021 / Accepted: June 25, 2021 / Published online: July 15, 2021

(c) The Author(s) 2021

\section{ABSTRACT}

Introduction: Subcutaneous galcanezumab was an effective, well-tolerated preventive treatment for adults with episodic (EM) or chronic migraine $(\mathrm{CM})$ in 4 phase 3 randomized controlled trials: EVOLVE-1, EVOLVE-2, REGAIN, and CONQUER. Number needed to treat (NNT) and to harm $(\mathrm{NNH})$ are metrics of effect size used to evaluate benefit-risk profiles. This study evaluated NNT, NNH, and benefit-risk profiles (measured as likelihood to be helped or harmed, $\mathrm{LHH}$ ) of galcanezumab $120 \mathrm{mg}$ versus placebo in patients with EM or CM.

Supplementary Information The online version contains supplementary material available at https:// doi.org/10.1007/s12325-021-01848-x.

L. Citrome

Department of Psychiatry \& Behavioral Sciences,

New York Medical College, Valhalla, NY, USA

M. Sánchez del Rio

Neurology Department, Clínica Universidad de

Navarra, Madrid, Spain

Y. Dong · R. M. Nichols · S. A. Foster .

V. L. Stauffer $(\square)$

Neuroscience Research, Lilly Corporate Center, Eli Lilly and Company, Indianapolis, IN 46285, USA e-mail: vstauffer@lilly.com

A. Tockhorn-Heidenreich

Eli Lilly and Company, Erl Wood Manor,

Windlesham, Surrey, UK
Methods: Primary efficacy outcomes were responses defined as $\geq 30 \%, \geq 50 \%$, and $\geq 75 \%$ reductions from baseline in number of monthly migraine headache days in patients with EM (EVOLVE-1; EVOLVE-2; CONQUER) and CM (REGAIN; CONQUER); corresponding NNTs to achieve respective responses; and corresponding NNHs for discontinuations due to adverse events (DCAEs) among the safety population. Secondary efficacy outcomes were responses for patients with $\geq 2$ failed prior preventive treatments due to lack of efficacy and/or for tolerability reasons. All LHHs were based on $\geq 50 \%$ response and DCAEs.

Results: During double-blind treatment periods with galcanezumab $120 \mathrm{mg}$, NNT to achieve $\geq 30 \%$ and $\geq 50 \%$ responses ranged from 4 to 10 and NNT to achieve $\geq 75 \%$ responses ranged from 5 to 23 in individual trials. NNH ranged from 93 to 1000, while LHH ranged from 18.6 to 104.6. NNTs were generally more robust among patients with EM than with $\mathrm{CM}$; however, in patients with failure of $\geq 2$ prior preventive treatments, NNTs to achieve $\geq 30 \%$ and $\geq 50 \%$ responses were similar between patients with CM and EM. NNHs were imputed as 1000 for both migraine types. Resulting LHHs were 178.8 (EM) and 127 (CM). Conclusion: Across 4 trials, galcanezumab $120 \mathrm{mg}$ demonstrated a favorable benefit-risk profile versus placebo, based on low NNTs to achieve response and high NNHs associated 
with DCAEs. LHH values consistently far exceeded 1.

Trial Registration Numbers: EVOLVE-1: ClinicalTrials.gov identifier, NCT02614183; EVOLVE-2: ClinicalTrials.gov identifier, NCT02614196; REGAIN: ClinicalTrials.gov identifier, NCT02614261; CONQUER: ClinicalTrials.gov identifier, NCT03559257.

Keywords: Benefit-risk profile; Chronic migraine; Effect size; Galcanezumab; Episodic migraine; Likelihood of help versus harm; Number needed to treat; Number needed to harm

\section{Key Summary Points}

\section{Why carry out this study?}

Migraine carries a high disease burden, and, although analgesic use for acute treatment of migraine is common, not all patients who might benefit from preventive therapy receive it.

Number needed to treat (NNT) and number needed to harm (NNH) are metrics of effect size that can be used to evaluate benefit-risk profiles and may help guide clinical decision-making.

This study evaluated the benefit-risk profile of galcanezumab using number needed to treat (NNT), number needed to harm $(\mathrm{NNH})$, and likelihood to be helped or harmed (LHH), as calculated from the phase 3 clinical trial program.

\section{What was learned from the study?}

Across 4 trials, galcanezumab treatment demonstrated robust NNTs versus placebo to achieve response and favorable NNHs versus placebo associated with discontinuations due to adverse events; in combination, these findings suggest galcanezumab is an effective preventive treatment for both chronic and episodic migraine with an excellent safety profile, where the benefits outweigh the possible risks associated with the drug.
More robust NNTs for galcanezumab versus placebo were observed for patients with episodic migraine (EM) than with chronic migraine (CM) overall; however, in patients with failure of $\geq 2$ prior preventive treatments, the NNTs versus placebo to achieve $\geq 30 \%$ and $\geq 50 \%$ response were similar between patients with EM and those with CM.

\section{INTRODUCTION}

Advances have recently been made regarding specific interventions to migraine prophylaxis which may carry efficacy and tolerability advantages over older approaches. Quantifying the benefit-risk can be challenging, particularly for novel mechanisms of action that may be unfamiliar to many practitioners. One such therapeutic target implicated in the pathogenesis of migraine is the calcitonin gene-receptor peptide (CGRP) [1]. Serum levels of CGRP are elevated during a migraine attack [2, 3]. Galcanezumab is a humanized monoclonal antibody that binds to CGRP ligand and blocks its binding to the receptor.

Initially, phase 2 studies of galcanezumab were conducted in patients with episodic migraine (EM) to establish proof of concept and dose finding. Preliminary efficacy results from the proof-of-concept study (vs. placebo, a significant mean change from baseline in the frequency of migraine headache days per 28-day period when assessed at 9-12 weeks) supported the likelihood of a role for CGRP in the pathogenesis of migraine, as well as support for more in-depth study of galcanezumab [4]. A later phase $2 b$ dose-finding study established that the once-monthly administration of $120 \mathrm{mg}$ galcanezumab significantly reduced the number of migraine headache days compared with placebo in patients with a history of migraine who completed treatment, with good tolerability and without any emergent safety issues [5].

Phase 3, double-blind, placebo-controlled studies have shown that the CGRP monoclonal 
antibodies approved in the United States and other countries (erenumab [6-8], fremanezumab $[9,10]$, galcanezumab [11-13], and eptinezumab [14, 15]) are efficacious in decreasing the frequency of monthly migraine headache days. Galcanezumab administered via subcutaneous injection (a single 240-mg loading dose, followed by 120-mg monthly doses) has been effective and well tolerated for the preventive treatment of EM and chronic migraine (CM) in 4 phase 3 studies: EVOLVE-1 (NCT02614183), EVOLVE-2 (NCT02614196), REGAIN (NCT02614261), and CONQUER (phase 3b, NCT03559257) [16-19]. In all 4 studies, the most common treatment-emergent adverse events (AEs) included injection site-related AEs (pain, erythema, pruritus, or swelling at the injection site), nasopharyngitis, sinusitis, upper respiratory tract infection, and influenza.

The objective of this study was to evaluate the benefit-risk profile of galcanezumab using number needed to treat (NNT), number needed to harm $(\mathrm{NNH})$, and likelihood to be helped or harmed $(\mathrm{LHH})[20,21]$, as calculated from the phase 3 clinical trial program.

\section{METHODS}

\section{Data Sources}

EVOLVE-1, EVOLVE-2, REGAIN, and CONQUER were 4 phase 3, multicenter, randomized, double-blind, placebo-controlled studies of adult patients with migraine [16-19]. The EM studies (EVOLVE-1 [19] and EVOLVE-2 [18]) examined whether galcanezumab $120 \mathrm{mg}$ or $240 \mathrm{mg}$ per month was superior to placebo in the preventive treatment of EM. In the CM study, REGAIN [16], galcanezumab was examined at doses of $120 \mathrm{mg}$ per month or $240 \mathrm{mg}$ per month, to see if it was superior to placebo in the preventive treatment of $\mathrm{CM}$. The $\mathrm{CON}$ QUER study [17] examined whether galcanezumab $120 \mathrm{mg}$ was superior to placebo in patients with treatment-resistant EM or CM. Additional details related to these clinical trials are provided in the published manuscripts for these trials [16-19]. Key study design characteristics and results from all 4 studies are summarized in Table 1 . The primary outcome of all 4 studies was the overall mean change from baseline in the number of monthly migraine headache days during the double-blind treatment period (6 months for EVOLVE-1 and -2, and 3 months for REGAIN and CONQUER).

The protocols for each study were reviewed and approved by the appropriate institutional or ethical review board (IRB) for each site. All studies described were conducted according to Good Clinical Practice and the Declaration of Helsinki guidelines. Patients provided written informed consent before undergoing study procedures. Adverse outcomes such as serious AEs were reported to the sponsor, IRB, and appropriate regulatory authority.

\section{Outcome Measures}

Primary efficacy outcomes for the present study were the observed $\geq 30 \%, \geq 50 \%$, and $\geq 75 \%$ response rates based on reductions from baseline in the number of monthly migraine headache days in patients with EM (EVOLVE-1, EVOLVE-2, and CONQUER) and patients with CM (REGAIN and CONQUER); estimation of corresponding NNTs to achieve $\geq 30 \%, \geq 50 \%$, and $\geq 75 \%$ response rates, respectively; and estimation of corresponding NNHs for discontinuations due to AEs among the safety population. Secondary efficacy outcomes were the estimation of $\geq 30 \%, \geq 50 \%, \quad$ and $\geq 75 \%$ response rates, as well as corresponding NNT values to achieve the respective response rates, and estimation of corresponding $\mathrm{NNH}$ values for discontinuations due to AEs in patients in all 4 clinical trials who had failure of $\geq 2$ prior preventive treatments versus placebo due to lack of efficacy and/or for tolerability reasons. LHH was defined as the ratio of NNH to NNT and was calculated using raw (unrounded) NNT and $\mathrm{NNH}$ values. The patient was considered more likely to be helped than harmed if the LHH was $>1$, and more likely to be harmed than helped if the LHH was $<1$. 


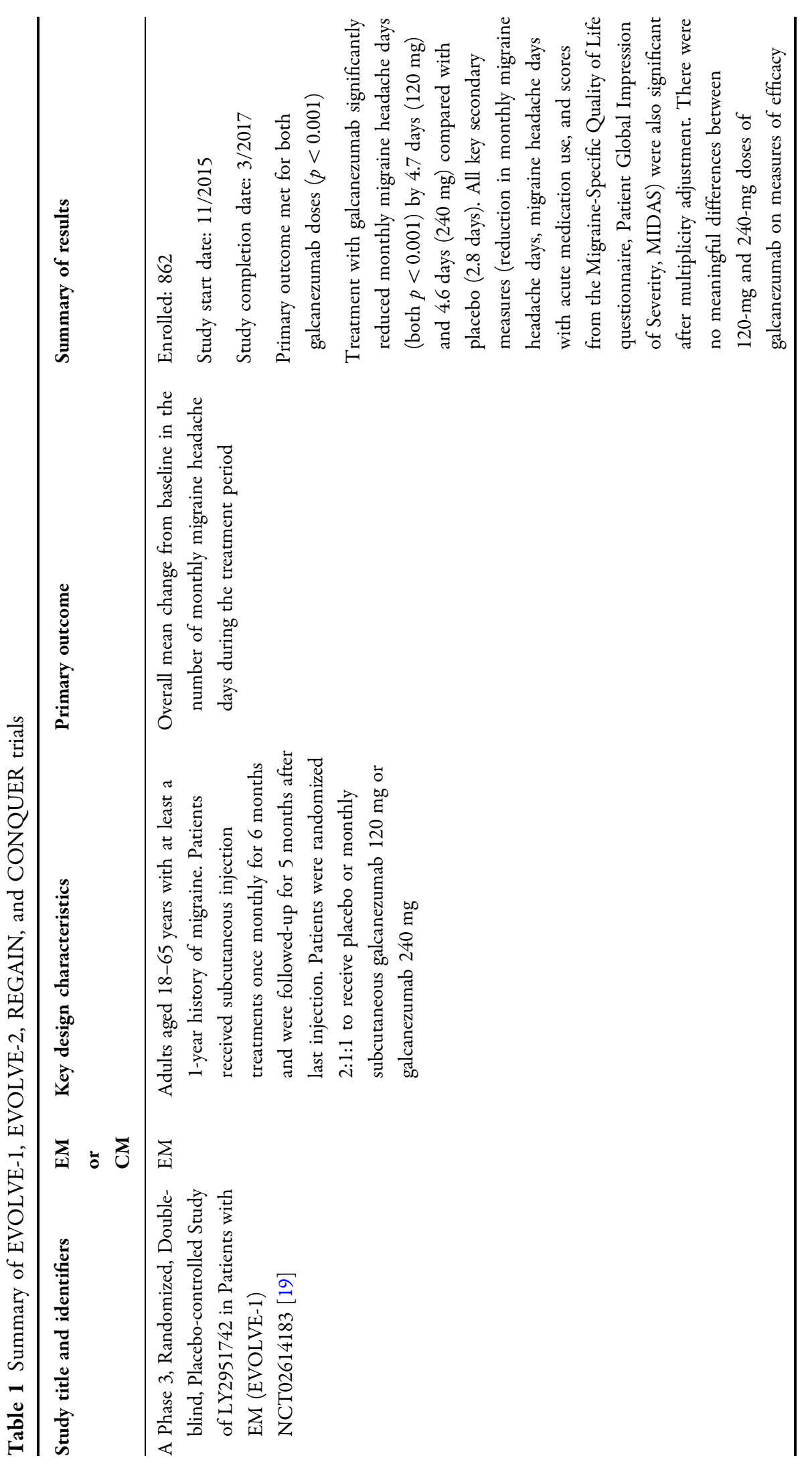




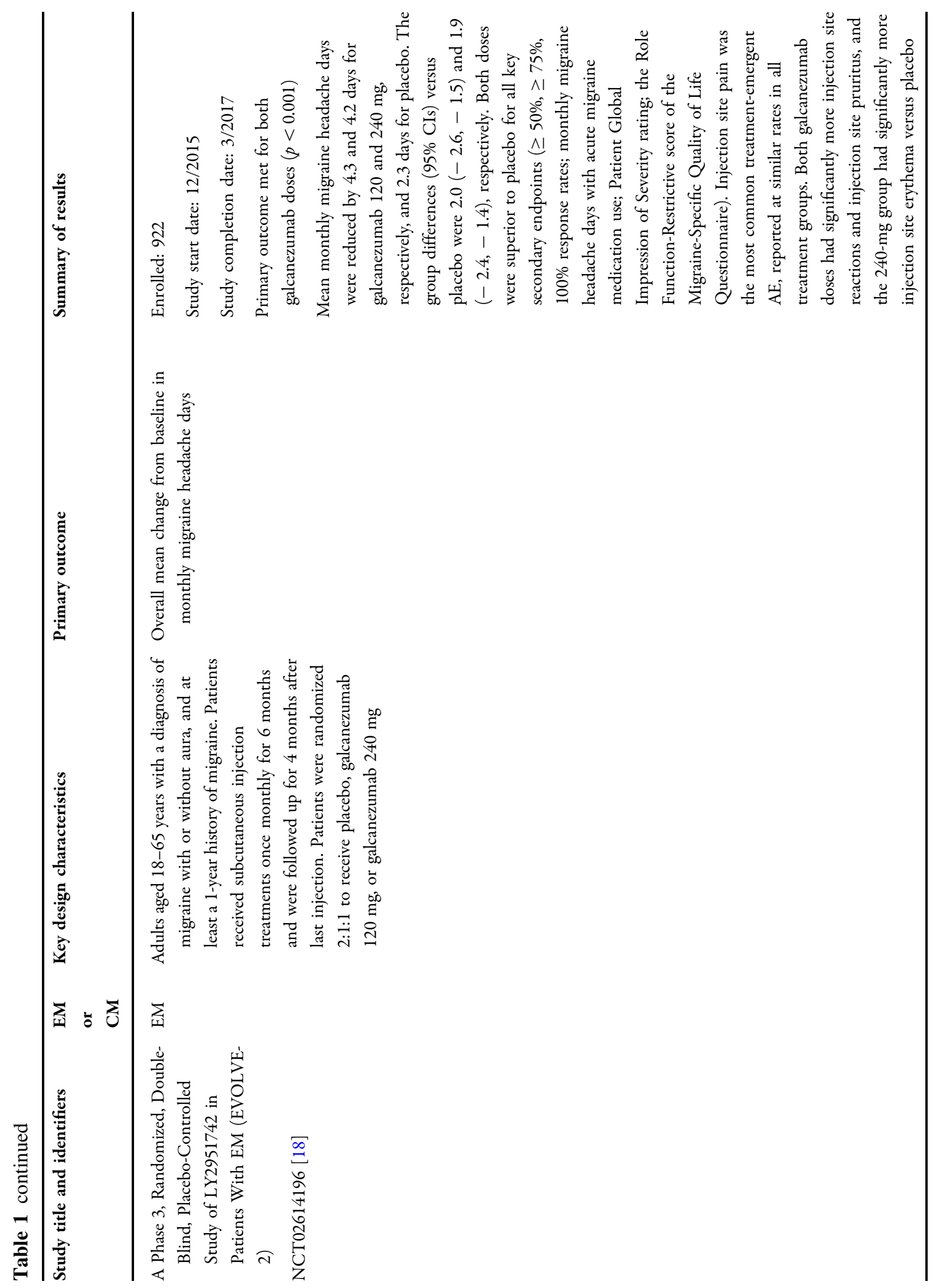




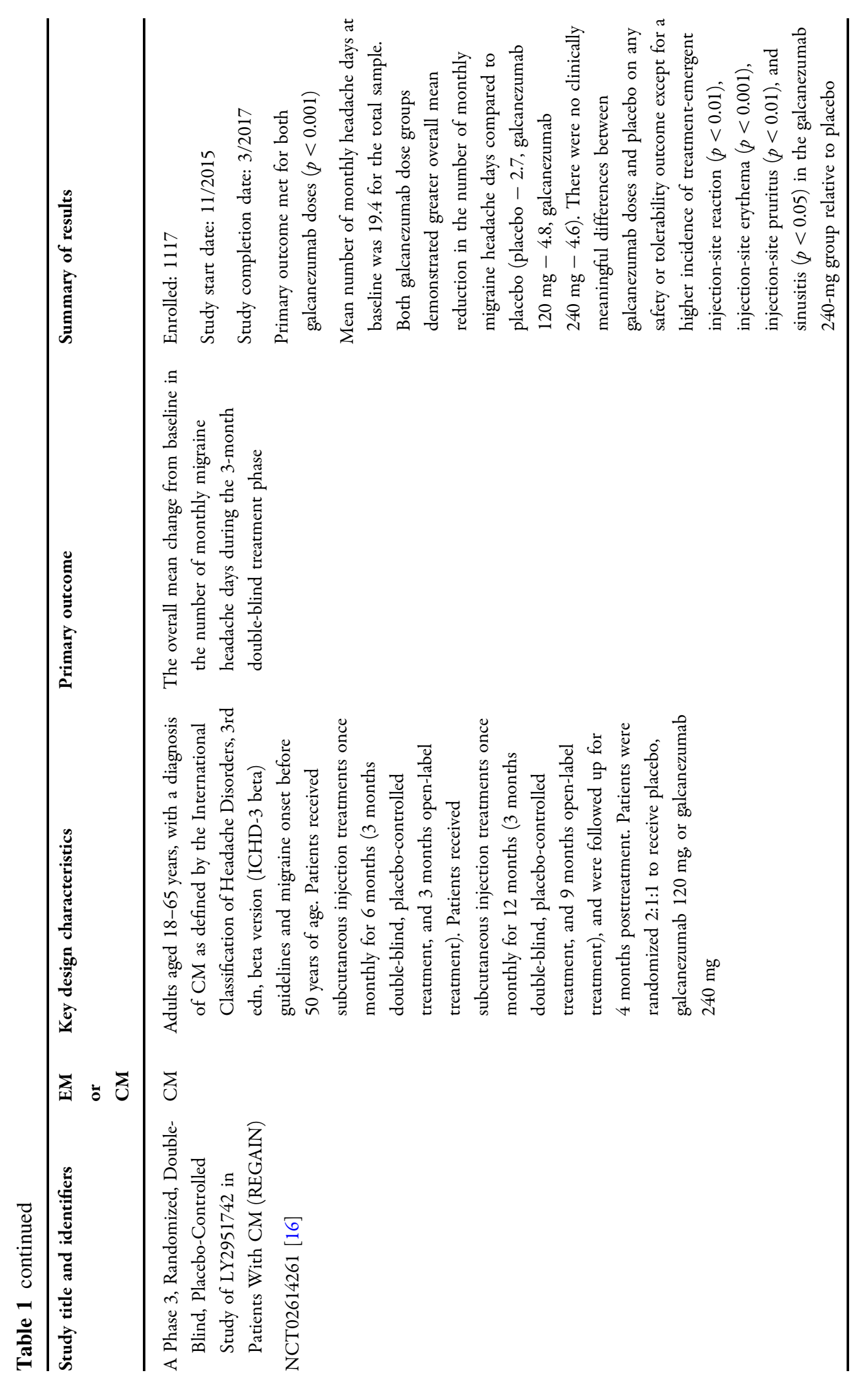




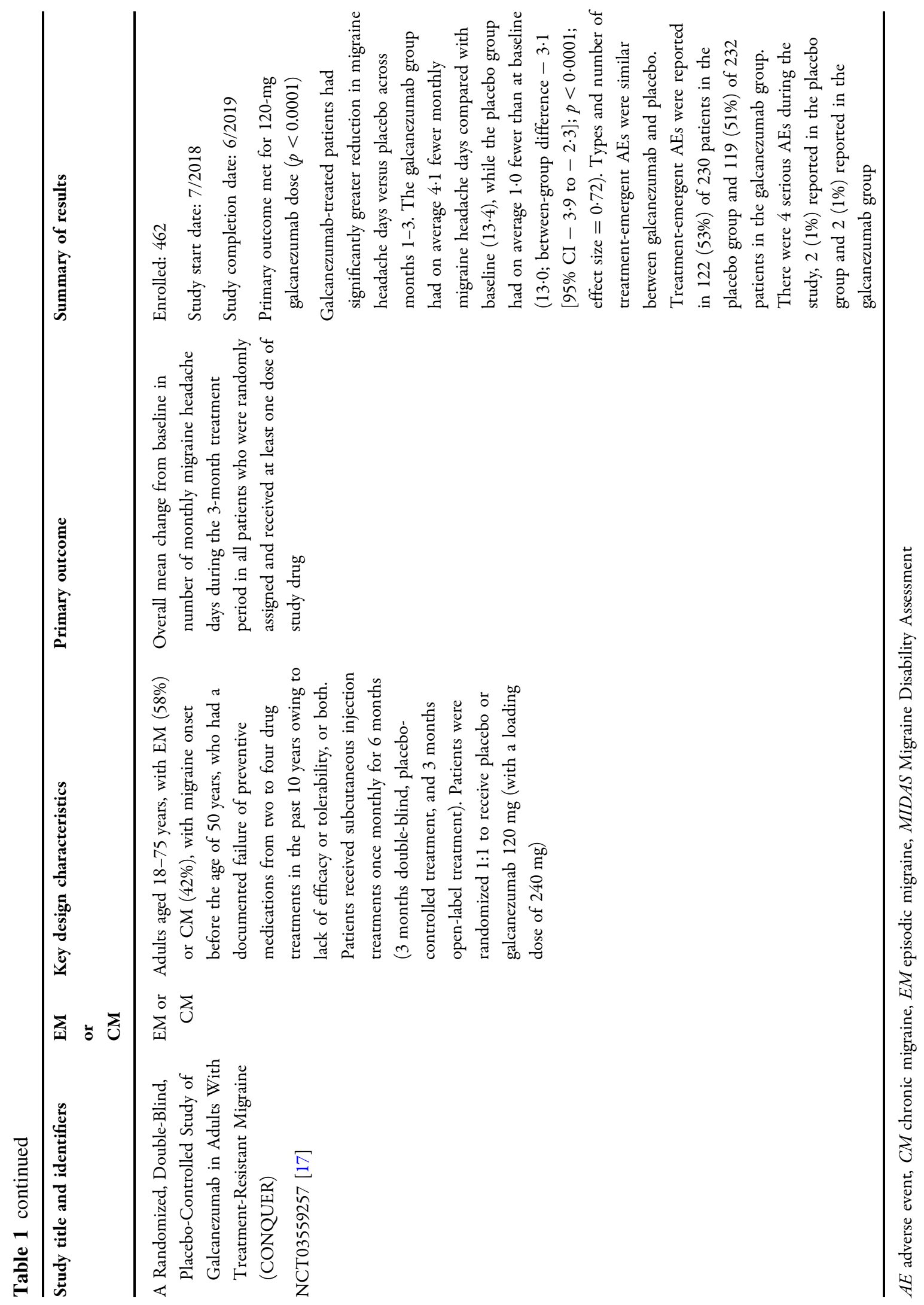




\section{Statistical Analysis}

Patients' demographic and disease characteristics at baseline were reported using descriptive statistics. Treatment comparisons were performed using analysis of variance model for continuous parameters and Fisher's exact test for categorical parameters at baseline.

In this post hoc analysis, NNT for efficacy outcomes, $\geq 30 \%$, $\geq 50 \%$, and $\geq 75 \%$ response rates, $\mathrm{NNH}$ for tolerability outcome, and discontinuations due to AEs were calculated for galcanezumab $120 \mathrm{mg}$ and $240 \mathrm{mg}$ versus placebo. The NNT or NNH is the inverse of the absolute difference in the incidence of outcomes between a given active treatment relative to placebo group. NNT and NNH were each rounded up to the next whole value. The precision around NNT and $\mathrm{NNH}$ was measured with 95\% confidence intervals (CIs) calculated using the modified Wilson score method without continuity correction [22]. If the lower bound (LB) and upper bound (UB) of the 95\% CI for the incidence difference had the same positive or negative sign (excluding 0), the 95\% $\mathrm{CI}$ of the NNT or NNH was the inverse of the UB and LB of incidence difference. Otherwise, a 95\% CI for the NNT or NNH was the union of less than $1 / \mathrm{LB}$ and greater than $1 / \mathrm{UB}$; in other words $(-\infty,-1 / \mathrm{LB}) \cup(1 / \mathrm{UB},+\infty)$. In instances where the rate of the $\mathrm{AE}$ or discontinuation because of an $\mathrm{AE}$ was greater with placebo than with galcanezumab, resulting in a "negative" $\mathrm{NNH}$, the $\mathrm{NNH}$ was redefined as having a value of 1000 (representing an absolute risk increase of 0.001, and with an incalculable 95\% CI) when determining the $\mathrm{LHH}$, as has been done in other reports of a similar nature [23].

The 95\% CI for LHH was calculated using a Bayesian approach with study summary data treated as the observations and a non-informative prior. The observed number of patients that achieved a response and the number of patients that discontinued treatment due to an AE from active treatment and placebo groups were assumed to follow 4 distinct binomial distributions. The posterior distribution of the incidence rate of an outcome from different treatment groups were beta distributions. LHH, a $2.5 \% \mathrm{LB}$ and a UB of $95 \%$ CI were estimated using Monte Carlo random sampling distributions. The 95\% CIs of $\mathrm{LHH}$ were wide and included zero because the incidence of discontinuations due to AEs between galcanezumab doses and the placebo group were very small positive percentages and close to zero. Therefore, the LHH value was reported but the corresponding 95\% CI of LHH was not presented.

In this analysis, NNT for each specific efficacy outcome and NNH for tolerability outcome, and the respective 95\% CIs, were calculated for galcanezumab $120 \mathrm{mg}$ versus placebo (for galcanezumab $240 \mathrm{mg}$ vs. placebo, see Supplementary Material) for the individual study for the overall population. The data were also reported among patients with at least 2 prior preventive medication failures due to inadequate efficacy or safety/tolerability in 6-month pooled EVOLVE-1 and -2, 3-month REGAIN, or 3-month CONQUER, respectively. In addition, the analysis was performed for pooled EM data at month 3 for EVOLVE-1, EVOLVE-2, and CONQUER studies, as well as the pooled CM data from REGAIN and CONQUER studies. This is a post hoc exploratory analysis and no formal hypothesis comparison or test was conducted. A two-sided significance level of 0.05 was considered. Statistical analyses were conducted using SAS v.7.1 (SAS Institute, Cary, NC, USA) and R v.3.6.3.

\section{RESULTS}

\section{Patient Demographics and Disease Characteristics}

Baseline demographics and disease characteristics were similar among patients with EM versus those with $\mathrm{CM}$ (Table 2). Among the most common pre-existing conditions $(\geq 10 \%$ of patients in EVOLVE-1 and/or CONQUER) were hypertension, anxiety, depression, seasonal allergy, drug hypersensitivity, back pain, gastroesophageal reflux disease, insomnia, and myopia. Across all 4 studies, migraine burden measured as the number of monthly migraine headache days and disability scores measured using the Migraine Disability Assessment (MIDAS) were greater among $\mathrm{CM}$ patients. 


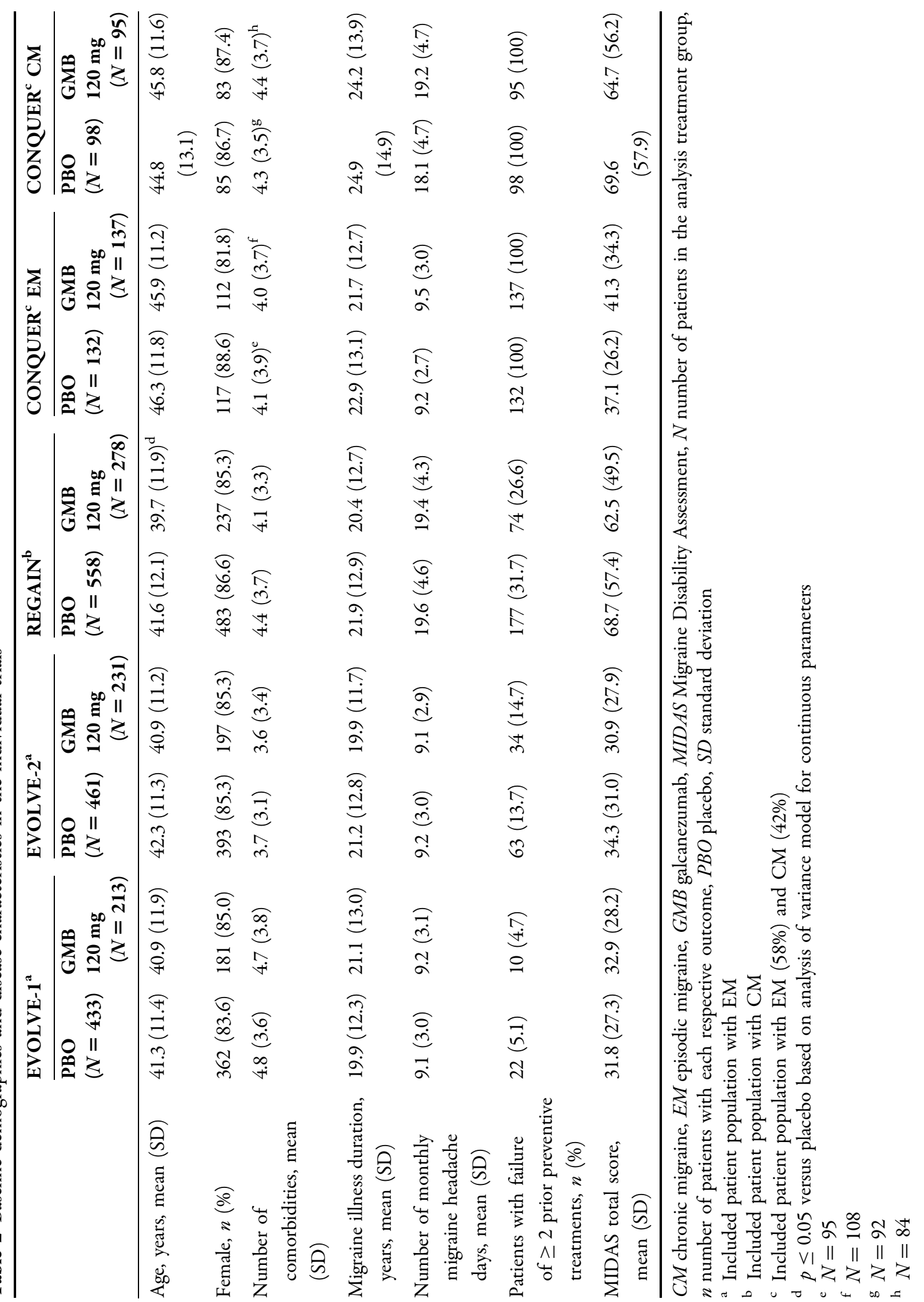


Patients in the REGAIN trial and patients with $\mathrm{CM}$ in the CONQUER trial treated with galcanezumab $120 \mathrm{mg}$ had 19.4 (4.3) and 19.2 (4.7) mean (SD) monthly migraine headache days, respectively; in comparison, all patients in EVOLVE-1, all patients in EVOLVE-2, and patients with EM in CONQUER treated with galcanezumab $120 \mathrm{mg}$ had 9.2 (3.1), 9.1 (2.9), and 9.5 (3.0) mean monthly migraine headache days, respectively. Mean (SD) MIDAS scores among REGAIN patients and CONQUER patients with $\mathrm{CM}$ treated with galcanezumab $120 \mathrm{mg}$ were 62.5 (49.5) and 64.7 (56.2), respectively; in comparison, mean MIDAS scores among all patients in EVOLVE-1, all patients in EVOLVE-2, and patients with EM in CONQUER were 32.9 (28.2), 30.9 (27.9), and 41.3 (34.3), respectively.

A greater proportion of patients in REGAIN (CM) than patients in EVOLVE-1 and -2 (EM) also had treatment failure of $\geq 2$ prior preventive treatments (Table 2). In CONQUER, the entire patient population had treatment failure of $\geq 2$ prior preventive treatments, $78 \%$ of which were due to inadequate or no response.

\section{Primary Analysis}

Over the durations of the 4 trials (months 1-6 for EVOLVE-1/-2 and months 1-3 for REGAIN and CONQUER), significantly higher percentages of patients treated with galcanezumab $120 \mathrm{mg}$ achieved $\geq 30 \%, \geq 50 \%, \quad$ and $\geq 75 \%$ responses versus patients who received placebo [16-19].

The NNTs to achieve responses during the double-blind treatment periods with galcanezumab $120 \mathrm{mg}$ were generally robust (i.e., low values) in the individual trials (Table 3). NNT $(95 \% \mathrm{CI})$ values at month 6 in EVOLVE-1 and -2 ranged from $5(4,7)$ to $8(5,18)$. In REGAIN, NNTs to achieve $\geq 30 \%$ and $\geq 50 \%$ response at month 3 were $8(5,20)$ and $10(6$, $30)$, respectively; however, the NNT value to achieve $\geq 75 \%$ response at month 3 was 23 $(-\infty,-134) \cup(12,+\infty)$. In CONQUER, NNTs to achieve $\geq 30 \%, \geq 50 \%$, and $\geq 75 \%$ responses at month 3 were $4(3,5), 5(4,8)$, and $12(8,38)$, respectively, for the overall study population (Table 3).

$\mathrm{NNH}$ values based on discontinuations due to AEs were high for galcanezumab $120 \mathrm{mg}$ across all 4 trials (Table 3). The NNH (95\% CI) values in EVOLVE-1 and EVOLVE-2 (patients with EM) were $93(-\infty,-67) \cup(22,+\infty)$ and $210(-\infty,-62) \cup(29,+\infty)$, respectively. In REGAIN (patients with CM), the NNH was 1000 (not evaluable [NE], NE). The overall NNH for CONQUER was $232(-\infty,-80) \cup(42,+\infty)$ (Table 3).

All LHH values presented were based on $\geq 50 \%$ response and discontinuations due to AEs. The LHH values for patients treated with galcanezumab $120 \mathrm{mg}$ were as follows: EVOLVE-1: 18.6; EVOLVE-2: 46.4; REGAIN: 104.6; and CONQUER: 49.7.

\section{Secondary Analysis}

In all 4 trials, responses were achieved among galcanezumab-treated patients with failures of $\geq 2$ prior treatments due to lack of efficacy or tolerability. Over the duration of each trial, greater percentages of galcanezumab-treated patients achieved $\geq 30 \%, \geq 50 \%$, and $\geq 75 \%$ responses versus patients who received placebo (Table 4). Additionally, higher percentages of patients with EM (EVOLVE-1 and -2 pooled; CONQUER EM) than with CM (REGAIN; CONQUER CM) achieved $\geq 30 \%, \geq 50 \%$, and $\geq 75 \%$ responses (Table 5).

\section{Effect Sizes Among Patients with Failure of $\geq 2$ Prior Preventive Treatments due to Reasons of Efficacy and/or Tolerability}

A subgroup analysis of patients who had experienced failure of $\geq 2$ prior preventive treatments due to reasons of efficacy and/or tolerability was conducted; this analysis focused on subgroups of the patient populations in EVOLVE-1 and -2 and REGAIN, while still including the entire patient population from CONQUER. Similarities in NNT values were noted between patients with EM versus CM. In the 2 pooled EVOLVE trials (EM patients), NNT values for galcanezumab $120 \mathrm{mg}$ to 
Table 3 The NNTs to achieve $\geq 30 \%, \geq 50 \%$, and $\geq 75 \%$ response rates and the NNHs for discontinuations due to aes in the individual trials

\begin{tabular}{|c|c|c|c|}
\hline \multirow{2}{*}{ Outcome } & GMB $120 \mathrm{mg}$ & PBO & \multirow[t]{2}{*}{ NNT or NNH $(95 \% \mathrm{CI})$ vs $\mathrm{PBO}$} \\
\hline & $\begin{array}{ll}n \quad N \\
\end{array}$ & $N$ & \\
\hline
\end{tabular}

EVOLVE-1, ${ }^{\mathrm{a}}$ Month 6

Efficacy

$\geq 30 \%$ response rate

$\geq 50 \%$ response rate

$\geq 75 \%$ response rate

Tolerability

Discontinuations due to AEs, all patients EVOLVE-2, ${ }^{a}$ Month 6

Efficacy

$\geq 30 \%$ response rate

$\geq 50 \%$ response rate

$\geq 75 \%$ response rate

Tolerability

Discontinuations due to AEs, all patients REGAIN, ${ }^{\text {b }}$ Month 3

Efficacy

$\geq 30 \%$ response rate

$\geq 50 \%$ response rate

$\geq 75 \%$ response rate

Tolerability

Discontinuations due to AEs, all patients CONQUER, ${ }^{\mathrm{c}}$ Month 3

Efficacy

$\geq 30 \%$ response rate

$\geq 50 \%$ response rate

$\geq 75 \%$ response rate

Tolerability

\section{NNT}

$$
\begin{array}{rrrrrrl}
143 & 177 & 80.8 \% & 226 & 342 & 66.1 \% & 7(5,14) \\
119 & 177 & 67.2 \% & 161 & 342 & 47.1 \% & 5(4,9) \\
87 & 177 & 49.2 \% & 88 & 342 & 25.7 \% & 5(4,7)
\end{array}
$$

$\mathrm{NNH}$

$$
\begin{array}{lllllll}
7 & 206 & 3.4 \% & 10 & 432 & 2.3 \% & 93(-\infty,-67) \cup(22,+\infty)
\end{array}
$$

NNT

$$
\begin{array}{rrrrrrl}
155 & 196 & 79.1 \% & 220 & 382 & 57.6 \% & 5(4,7) \\
127 & 196 & 64.8 \% & 163 & 382 & 42.7 \% & 5(4,8) \\
76 & 196 & 38.8 \% & 95 & 382 & 24.9 \% & 8(5,18)
\end{array}
$$

$\mathrm{NNH}$

$5 \quad 226 \quad 2.2 \% \quad 8 \quad 461 \quad 1.7 \% \quad 210(-\infty,-62) \cup(29,+\infty)$

NNT

$$
\begin{array}{rrrrrrl}
136 & 256 & 53.1 \% & 202 & 498 & 40.6 \% & 8(5,20) \\
90 & 256 & 35.2 \% & 123 & 498 & 24.7 \% & 10(6,30) \\
34 & 256 & 13.3 \% & 44 & 498 & 8.8 \% & 23(-\infty,-134) \cup(12,+\infty) \\
& & & & & & \mathrm{NNH} \\
1 & 273 & 0.4 \% & 6 & 558 & 1.1 \% & 1000(\mathrm{NE}, \mathrm{NE})
\end{array}
$$

\section{NNT}

$$
\begin{array}{rrrrrrl}
136 & 224 & 60.7 \% & 72 & 224 & 32.1 \% & 4(3,5) \\
87 & 224 & 38.8 \% & 39 & 224 & 17.4 \% & 5(4,8) \\
33 & 224 & 14.7 \% & 14 & 224 & 6.3 \% & 12(8,38)
\end{array}
$$

$\mathrm{NNH}$ 
Table 3 continued

\begin{tabular}{|c|c|c|c|c|c|c|}
\hline \multirow[t]{2}{*}{$\overline{\text { Outcome }}$} & \multicolumn{2}{|c|}{ GMB $120 \mathrm{mg}$} & \multicolumn{3}{|c|}{ PBO } & \multirow[t]{2}{*}{ NNT or NNH $(95 \% \mathrm{CI})$ vs PBO } \\
\hline & $N$ & $\%$ & & & & \\
\hline Discontinuations due to AEs, all patients & 1232 & $0.4 \%$ & 0 & 230 & $0 \%$ & $232(-\infty,-80) \cup(42,+\infty)$ \\
\hline \multicolumn{7}{|c|}{$\begin{array}{l}A E \text { adverse event, } C I \text { confidence intervals, } C M \text { chronic migraine, } E M \text { episodic migraine, } G M B \text { galcanezumab, } N \text { number of } \\
\text { patients in the analysis treatment group, } n \text { number of patients with each respective outcome, } N E \text { not evaluable, } \\
N N H \text { number needed to harm, } N N T \text { number needed to treat, } P B O \text { placebo } \\
\text { a Included patient population with EM; based on data from Month } 6 \\
\text { b Included patients with CM; based on data from Month } 3 \\
\text { c Included patient population with EM }(58 \%) \text { and CM }(42 \%) \text {; based on data from Month } 3\end{array}$} \\
\hline
\end{tabular}

achieve $\geq 30 \%, \geq 50 \%, \quad$ and $\geq 75 \%$ responses ranged from $4(3,7)$ to $5(3,22)$ (Table 4$)$. NNT values for galcanezumab $120 \mathrm{mg}$ to achieve $\geq 30 \%$ and $\geq 50 \%$ responses were similarly low for patients with EM from the CONQUER trial; however, the NNT value for galcanezumab $120 \mathrm{mg}$ to achieve $\geq 75 \%$ response in CONQUER was $15(-\infty$, $-81) \cup(7,+\infty)$. Among patients with CM treated with galcanezumab $120 \mathrm{mg}$ in REGAIN and CONQUER, NNT values were generally low and the values to achieve each level of response were similar, although they were higher for the $\geq 75 \%$ response in each trial than for the $\geq 30 \%$ and $\geq 50 \%$ responses (Table 4). When patients in CONQUER were stratified by migraine type, NNT values to achieve $\geq 30 \%$ and $\geq 50 \%$ responses at month 3 were $4(3,6)$ and $6(4,11)$, respectively, for patients with EM and $4(3,6)$ and $5(3,9)$, respectively, for patients with CM; NNT values to achieve $\geq 75 \%$ response were $15(-\infty,-81) \cup(7,+\infty)$ and 10 $(6,58)$ for patients with EM and $\mathrm{CM}$, respectively (Table 4).

In both pooled EVOLVE-1 and -2 (patients with EM, month 6) and REGAIN (patients with $\mathrm{CM}$, month 3), NNH values based on $\geq 50 \%$ response and discontinuations due to AEs were imputed as 1000 (NE, NE) for each, suggesting galcanezumab $120 \mathrm{mg}$ is highly tolerable for patients with either migraine type. These findings were further supported by the results of the subanalysis of patients in CONQUER (all patients with EM or CM who had failure of $\geq 2$ prior preventive treatments) at month $3: \mathrm{NNH}$ was not evaluable for patients with EM, and was $95(-\infty,-35) \cup(18,+\infty)$ in patients with $\mathrm{CM}$ (Table 4 ). Based on $\geq 50 \%$ responses and discontinuations due to AEs, these findings resulted in overall LHH values of 304.8 in EVOLVE-1 and -2 pooled, 160.6 in REGAIN, and 49.7 in CONQUER.

\section{3-Month Data from all 4 Trials Stratified by Migraine Type (EM vs CM)}

Overall NNTs for all tested response groups were relatively low for all migraine patients; however, they were generally higher among patients with CM than among those with EM (Table 5). NNTs to achieve $\geq 75 \%$ response were greatest for patients with each migraine type (EM: 10 [7, 16]; CM: 19 [11, 109]). NNH values based on $\geq 50 \%$ response and discontinuations due to AEs were similarly high for both migraine types, and were imputed as 1000 (NE, NE) for each. Based on $\geq 50 \%$ response and discontinuations due to AEs, these findings resulted in overall LHH values of 178.8 for patients with EM and 127 for patients with CM.

\section{Pooled 6-Month Data for EVOLVE-1 and EVOLVE-2}

In the pooled EVOLVE-1 and EVOLVE-2 trials, the NNT (95\% CI) value for galcanezumab $120 \mathrm{mg}$ to achieve $\geq 50 \%$ response at month 6 was $4(3,7)$, and the $\mathrm{NNH}(95 \% \mathrm{CI})$ value was imputed as 1000 (NE, NE) (Table 4). Based on $\geq 50 \%$ response and discontinuations due to AEs, these findings resulted in an overall LHH 
Table 4 The NNTs to achieve $\geq 30 \%, \geq 50 \%$, and $\geq 75 \%$ response rates in patients with failure of $\geq 2$ prior preventive treatments due to lack of efficacy and/or tolerability

\begin{tabular}{|c|c|c|c|c|c|c|}
\hline \multirow[t]{2}{*}{ Outcome } & \multicolumn{2}{|c|}{ GMB $120 \mathrm{mg}$} & \multicolumn{3}{|c|}{ PBO } & \multirow[t]{2}{*}{ NNT or NNH $(95 \% \mathrm{CI})$ vs $\mathrm{PBO}$} \\
\hline & $N$ & $\%$ & $n$ & $N$ & $\%$ & \\
\hline
\end{tabular}

Pooled EVOLVE-1 and EVOLVE-2, ${ }^{a}$ month 6

Efficacy

$\geq 30 \%$ response rate

$\geq 75 \%$ response rate

TOLERABILITY

DCAE, all patients

REGAIN, ${ }^{\mathrm{b}}$ month 3

Efficacy

$\geq 30 \%$ response rate

$\geq 50 \%$ response rate

$\geq 75 \%$ response rate

Tolerability

DCAE, all patients $\geq 50 \%$ response rate

28

31

49

28

18

49

$63.3 \%$

32

75

$42.7 \%$

NNT

$49 \quad 36.7 \%$

20

75

$26.7 \%$

$5(3,22)$

$49 \quad 36.7 \%$

8

75

$10.7 \%$

$4(3,7)$

$4(3,9)$

$N N H$

$0 \quad 51 \quad 0 \%$

1

$92 \quad 0.01 \%$

1000 (NE, NE)

NNT

$\begin{array}{rrrrrrl}32 & 69 & 46.4 \% & 40 & 167 & 24.0 \% & 5(3,11) \\ 21 & 69 & 30.4 \% & 24 & 167 & 14.4 \% & 7(4,29) \\ 6 & 69 & 8.7 \% & 5 & 167 & 3.0 \% & 18(-\infty,-28) \cup(9,+\infty) \\ & & & & & & N N H \\ 0 & 73 & 0 \% & 2 & 177 & 1.1 \% & 1000(\mathrm{NE}, \mathrm{NE})\end{array}$

CONQUER EM, ${ }^{\mathrm{a}}$ month 3

Efficacy

$\geq 30 \%$ response rate

85

136

$62.5 \%$

45

$129 \quad 34.9 \%$

NNT

$\geq 50 \%$ response rate

55

136

$40.4 \%$

27

129

$20.9 \%$

$4(3,6)$

$\geq 75 \%$ response rate

22

136

$16.2 \%$

12

129

$9.3 \%$

$6(4,11)$

Tolerability

DCAE, all patients

0

$137 \quad 0 \%$

0

132

$0 \%$

NNH

CONQUER CM, ${ }^{\mathrm{b}}$ month 3

Efficacy

$\geq 30 \%$ response rate

$\geq 50 \%$ response rate

$\geq 75 \%$ response rate

Tolerability

$\begin{array}{rrrrrrl}51 & 88 & 58.0 \% & 27 & 95 & 28.4 \% & 4(3,6) \\ 32 & 88 & 36.4 \% & 12 & 95 & 12.6 \% & 5(3,9) \\ 11 & 88 & 12.5 \% & 2 & 95 & 2.1 \% & 10(6,58)\end{array}$

NNT

$N N H$ 
Table 4 continued

\begin{tabular}{|c|c|c|c|c|c|c|c|}
\hline \multirow[t]{2}{*}{ Outcome } & \multicolumn{3}{|c|}{ GMB $120 \mathrm{mg}$} & \multicolumn{3}{|c|}{ PBO } & \multirow[t]{2}{*}{ NNT or NNH $(95 \% \mathrm{CI})$ vs $\mathrm{PBO}$} \\
\hline & $n$ & $N$ & $\%$ & $n$ & $N$ & $\%$ & \\
\hline DCAE, all patients & 1 & 95 & $1.1 \%$ & 0 & 98 & $0 \%$ & $95(-\infty,-35) \cup(18,+\infty)$ \\
\hline
\end{tabular}

$C I$ confidence intervals, $C M$ chronic migraine, DCAEs discontinuations due to adverse events, $E M$ episodic migraine, $G M B$ galcanezumab, $N$ number of patients in the analysis treatment group, $n$ number of patients with each respective outcome, $N E$ not evaluable, $N N H$ number needed to harm, $N N T$ number needed to treat, $P B O$ placebo

${ }^{a}$ Included patients with EM

b Included patients with $\mathrm{CM}$

value of 304.8 across the 2 pooled trials at month 6 .

\section{DISCUSSION}

This analysis adds support to ongoing assertions that NNT and NNH can be used to evaluate benefit-risk profiles and help guide clinical decision-making across a variety of specialty areas and scenarios [24-29]. Although NNT and $\mathrm{NNH}$ estimates are calculated by comparing groups, ultimately the information is applied when treating individuals, including the communication of benefits and risks [30]. The philosophy of evidence-based medicine/practice is to integrate clinical data/judgment with relevant scientific evidence and the patient's own individual values and preferences [31]. NNT and $\mathrm{NNH}$ can inform the clinician about the propensity for an agent to have a large or small effect size on the outcome of interest, but it cannot be taken out of context, such as patient baseline, patient history, and patient preference.

Across all 4 trials, galcanezumab demonstrated a favorable benefit-risk profile compared with placebo, as assessed by low NNT values to achieve responses and high NNH values associated with discontinuations due to AEs, and thus LHH values far exceeding 1 . Overall, more robust (i.e., lower) NNT values were observed for patients with EM (all patients in EVOLVE-1 and -2 and patients with EM in CONQUER) than for those with CM (all patients in REGAIN and patients with CM in CONQUER). NNT values to achieve $\geq 30 \%$ and $\geq 50 \%$ responses in patients with failure of $\geq 2$ prior preventive treatments were similar between patients with CM and EM for the galcanezumab 120-mg dose group. Although the single discontinuation due to an $\mathrm{AE}$ in CONQUER precluded the calculation of meaningful $\mathrm{NNH}$ (and therefore LHH) values when patients were stratified by migraine type, the low NNT values and the low number of discontinuations due to AEs observed in CONQUER do support positive benefit-risk profiles for both migraine types.

The variation among NNT values may have been due to differences in disease burden at baseline (i.e., migraine headache days), and differences among both NNT and NNH values may have been due to the shorter treatment duration associated with patients with $\mathrm{CM}$ versus those with EM (i.e., 3 vs. 6 months). In addition, the percentages of patients who discontinued trials due to AEs were not significantly higher for galcanezumab versus placebo in any of the 4 trials, which makes the difference in $\mathrm{NNH}$ estimates highly variable.

LHH values based on $\geq 50 \%$ response and discontinuations due to AEs ranged from 18.6 to 104.6 across all individual studies. The highest LHH value for galcanezumab $120 \mathrm{mg}$ was observed in REGAIN, a potential artifact of the shorter double-blind study period (3 vs. 6 months in EVOLVE-1 and -2).

A benefit-risk assessment of several current preventive treatments for migraine (erenumab, topiramate, onabotulinumtoxinA, and propranolol) found that each of these four drugs were more likely to help than harm migraine patients, and the benefit-risk profile for erenumab was orders of magnitude more positive 
Table 5 The NNTs to achieve $\geq 30 \%, \geq 50 \%$, and $\geq 75 \%$ response in migraine headache days and the NNHs for DCAEs from pooled 3-month data from patients with episodic migraine (From EVOLVE-1/-2 and CONQUER) and chronic migraine (From REGAIN and CONQUER)

\begin{tabular}{|c|c|c|c|c|c|c|}
\hline \multirow[t]{2}{*}{ Outcome } & \multicolumn{2}{|c|}{ GMB $120 \mathrm{mg}$} & \multicolumn{3}{|c|}{ PBO } & \multirow[t]{2}{*}{ NNT or $\mathrm{NNH}(95 \% \mathrm{CI})$ vs $\mathrm{PBO}$} \\
\hline & $N$ & $\%$ & $n$ & $N$ & $\%$ & \\
\hline
\end{tabular}

Episodic migraine: pooled EVOLVE-1, EVOLVE-2 and CONQUER EM, month 3

\begin{tabular}{lccccccl} 
Efficacy & & & & & & & \multicolumn{2}{l}{ NT } \\
$\geq 30 \%$ response rate & 370 & 543 & $68.1 \%$ & 465 & 912 & $51.0 \%$ & $6(5,9)$ \\
$\geq 50 \%$ response rate & 290 & 543 & $53.4 \%$ & 324 & 912 & $35.5 \%$ & $6(5,8)$ \\
$\geq 75 \%$ response rate & 160 & 543 & 29.5 & 168 & 912 & 18.4 & $10(7,16)$ \\
Tolerability & & & & & & & NNH \\
DCAE, all patients & 7 & 569 & $1.2 \%$ & 14 & 1025 & $1.4 \%$ & 1000 (NE, NE)
\end{tabular}

Chronic migraine: pooled REGAIN and CONQUER CM, month 3

\begin{tabular}{|c|c|c|c|c|c|c|c|}
\hline EFFICACY & & & & & & & $N N T$ \\
\hline$\geq 30 \%$ response rate & 187 & 344 & $54.4 \%$ & 229 & 593 & $38.6 \%$ & $7(5,11)$ \\
\hline$\geq 50 \%$ response rate & 122 & 344 & $35.5 \%$ & 135 & 593 & $22.8 \%$ & $8(6,16)$ \\
\hline$\geq 75 \%$ response rate & 45 & 344 & $13.1 \%$ & 46 & 593 & $7.8 \%$ & $19(11,109)$ \\
\hline Tolerability & & & & & & & $N N H$ \\
\hline DCAE, all patients & 2 & 368 & $0.5 \%$ & 6 & 656 & $0.9 \%$ & $1000(\mathrm{NE}, \mathrm{NE})$ \\
\hline
\end{tabular}

$C I$ confidence intervals, $C M$ chronic migraine, DCAEs discontinuations due to adverse events, $E M$ episodic migraine, $G M B$ galcanezumab, $N$ number of patients in the analysis treatment group, $n$ number of patients with each respective outcome, $N E$ not evaluable, $N N H$ number needed to harm, $N N T$ number needed to treat, $P B O$ placebo

than those calculated for topiramate, onabotulinumtoxinA, and propranolol [23]. The differences observed in LHH between erenumab and topiramate, onabotulinumtoxinA, and propranolol were primarily supported by large differences in $\mathrm{NNH}$; in other words, the tolerability of erenumab appeared to be better than the tolerability of topiramate, onabotulinumtoxin A, and propranolol [23, reviewed in 32].

Drellia et al. recently conducted an LHH analysis of anti-CGRP antibodies and frequently used preventives for migraine [33]. Because there are no head-to-head comparisons with established treatments, their analysis helps to compare the absolute differences in benefit-risk ratios between drugs. Anti-CGRP antibodies at all tested doses had higher LHH values than propranolol or topiramate for EM prevention and onabotulinumtoxinA or topiramate for CM prevention [33]. These findings predict patient satisfaction and a better adherence profile for anti-CGRP antibodies. The results we describe here are in line with the findings of Drellia et al. regarding the NNT and $\mathrm{NNH}$ to achieve $\geq 50 \%$ response ( $\geq 50 \%$ reduction in migraine headache days) and the resulting LHH of galcanezumab in EVOLVE-1/2 and REGAIN [33], and we build on those findings by also evaluating pooled EVOLVE-1/-2 results, CONQUER results stratified by migraine type (EM vs. CM), and pooled 3-month results from all 4 galcanezumab studies stratified by migraine type. In addition, we have included analogous calculations for the NNT values to achieve $\geq 30 \%$ and $\geq 75 \%$ responses, and found that the NNTs required to achieve all tested response levels 
were similarly low, with the notable exception of the NNT to achieve $\geq 75 \%$ response in REGAIN (patients with CM; NNT $=23$ ).

\section{Limitations}

NNT and NNH values are subject to limitations. Values can vary with baseline risk, length of treatment, response threshold definitions, and length of follow-up. In addition, regarding $\mathrm{NNH}$, if the treatment arm has a lower rate of discontinuation than the placebo arm, it yields a negative absolute risk reduction, and hence results in a difficult to interpret "negative" NNH value; arbitrarily assigning an $\mathrm{NNH}$ value of 1000 under these circumstances is a workaround in order to estimate the LHH. Moreover, for small event rate differences, 95\% CI values generally span infinity, and thus inherently the $\mathrm{NNH}$ estimate would be imprecise. Because of these limitations, NNT and NNH values (and the LHH values calculated from them) should be interpreted with caution, particularly across trials and interventions. In the absence of direct head-to-head studies, no definitive conclusions regarding one treatment being better than another should be drawn from reports of NNT and NNH values across various studies. Analyses are post hoc. Due to the nature of NNT/NNH analysis, the data analyzed in this study are limited to dichotomous outcomes. The results may not be generalizable to patients outside the confines of a clinical trial; this is always a concern for results of randomized controlled trials because of the strict inclusion/exclusion criteria that these studies require. Reasons for clinical trial discontinuation can be complex, so the $\mathrm{NNH}$ for discontinuations due to AEs in the study may not always generalize to overall tolerability in clinical practice. The brief durations of the available controlled studies limit the sensitivity of calculating $\mathrm{NNH}$ for delayed adverse outcomes beyond 3-6 months, and the relatively small sample sizes of the studies limit sensitivity of calculating $\mathrm{NNH}$ for uncommon adverse outcomes and sub-population effects.

\section{CONCLUSIONS}

Across 4 trials, in comparison to placebo galcanezumab showed robust NNTs to achieve response rates and favorable NNHs associated with discontinuations due to AEs. These findings suggest galcanezumab is associated with an advantageous benefit-risk profile. In patients with failure of $\geq 2$ prior preventive treatments, the NNTs to achieve $\geq 30 \%$ and $\geq 50 \%$ response rates were similar between patients with $\mathrm{CM}$ (REGAIN and CONQUER CM) and those with EM (EVOLVE-1/2 and CONQUER EM) who received a single loading dose of $240 \mathrm{mg}$ galcanezumab followed by $120 \mathrm{mg}$ monthly thereafter (Table 4). More robust (i.e., lower) NNTs were observed for patients with EM (EVOLVE-1/2 and CONQUER EM) than for those with CM (REGAIN and CONQUER CM) (Table 5). The percentages of discontinuations due to AEs were not statistically significantly higher for galcanezumab versus placebo in the EVOLVE-1/2, REGAIN, and CONQUER trials.

Therefore, this analysis shows galcanezumab is an effective preventive treatment for both chronic and episodic migraine with an excellent safety profile, where the benefits outweigh the possible risks associated with the drug.

\section{ACKNOWLEDGEMENTS}

We thank the patients, their families, the study sites, and the study personnel who participated in these clinical trials.

Funding. This study and the journal's Rapid Service and Open Access Fees were funded by Eli Lilly and Company, Indianapolis, IN, USA. The authors received no financial support for the research, authorship, and/or publication of this article.

Medical Writing, Editorial, and Other Assistance. Medical writing support was provided by Regina E. Burris, PhD, and editorial support was provided by Antonia Baldo, both of Syneos Health. Medical writing and editorial support were funded by Eli Lilly and Company, 
Indianapolis, IN, USA in accordance with Good Publication Practice (GPP3) guidelines (http:// www.ismpp.org/gpp3).

Authorship. All named authors meet the International Committee of Medical Journal Editors (ICMJE) criteria for authorship for this article, take responsibility for the integrity of the work as a whole, and have given their approval for this version to be published.

Authors' Contributions. Leslie Citrome: Study concept and design, analysis and interpretation of data, drafting of manuscript, critical revision of manuscript for important intellectual content. Margarita Sánchez del Rio: Analysis and interpretation of data, critical revision of manuscript for important intellectual content. Yan Dong: Study concept, analysis and interpretation of data, critical revision of manuscript for important intellectual content. Russell M. Nichols: Interpretation of data, critical revision of manuscript for important intellectual content. Antje Tockhorn-Heidenreich: Interpretation of data, critical revision of manuscript for important intellectual content. Shonda A. Foster: Interpretation of data, critical revision of manuscript for important intellectual content. Virginia L. Stauffer: Study concept and design, interpretation of data, critical revision of manuscript for important intellectual content.

Prior Presentation. Some of the data contained in this article were first presented at the 19th Congress of the International Headache Society, September 5-8, 2019, in Dublin, Ireland.

Disclosures. Leslie Citrome in the past 12 months has served as consultant: AbbVie, Acadia, Alkermes, Allergan, Angelini, Astellas, Avanir, Axsome, BioXcel, Boehringer Ingelheim, Cadent Therapeutics, Eisai, Impel, IntraCellular Therapies, Janssen, Karuna, Lundbeck, Lyndra, Medavante-ProPhase, Merck, Neurocrine, Noven, Otsuka, Ovid, Relmada, Sage, Sunovion, Teva, University of Arizona, and oneoff ad hoc consulting for individuals/entities conducting marketing, commercial, or scientific scoping research; speaker: AbbVie, Acadia, Alkermes, Allergan, Angelini, Eisai, Intra-Cellular Therapies, Janssen, Lundbeck, Neurocrine, Noven, Otsuka, Sunovion, Takeda, Teva, and CME activities organized by medical education companies such as Medscape, NACCME, NEI, Vindico, and Universities and Professional Organizations/Societies; owns stocks (small number of shares of common stock): BristolMyers Squibb, Eli Lilly, J \& J, Merck, Pfizer purchased $>10$ years ago; and received royalties: Wiley (Editor-in-Chief, International Journal of Clinical Practice, through end 2019), UpToDate (reviewer), Springer Healthcare (book), Elsevier (Topic Editor, Psychiatry, Clinical Therapeutics). Margarita Sánchez del Rio has received fees from Allergan, Eli-Lilly, Novartis, and Teva as a speaker or for her participation in advisory boards. Yan Dong, Russell M. Nichols, Shonda A. Foster, and Virginia L. Stauffer are full-time employees of Eli Lilly and Company, Indianapolis, IN, USA, and minority holders of company stock. Antje TockhornHeidenreich is a full-time employee of Eli Lilly and Company, Erl Wood Manor, Surrey, UK.

Compliance with Ethics Guidelines. The protocols for each study were reviewed and approved by the appropriate institutional or ethical review board for each site. All studies described were conducted according to Good Clinical Practice and the Declaration of Helsinki guidelines. Patients provided written informed consent before undergoing study procedures. Adverse outcomes such as serious AEs were reported to the sponsor, IRB and appropriate regulatory authority.

Data Availability. Eli Lilly and Company provides access to all individual participant data collected during the trial, after anonymization, with the exception of pharmacokinetic or genetic data. Data are available to request 6 months after the indication studied has been approved in the US and EU and after primary publication acceptance, whichever is later. No expiration date of data requests is currently set once data are made available. Access is provided after a proposal has been approved by an independent review committee identified for this 
purpose and after receipt of a signed data sharing agreement. Data and documents, including the study protocol, statistical analysis plan, clinical study report, blank or annotated case report forms, will be provided in a secure data sharing environment. For details on submitting a request, see the instructions provided at www. vivli.org.

Open Access. This article is licensed under a Creative Commons Attribution-NonCommercial 4.0 International License, which permits any non-commercial use, sharing, adaptation, distribution and reproduction in any medium or format, as long as you give appropriate credit to the original author(s) and the source, provide a link to the Creative Commons licence, and indicate if changes were made. The images or other third party material in this article are included in the article's Creative Commons licence, unless indicated otherwise in a credit line to the material. If material is not included in the article's Creative Commons licence and your intended use is not permitted by statutory regulation or exceeds the permitted use, you will need to obtain permission directly from the copyright holder. To view a copy of this licence, visit http:// creativecommons.org/licenses/by-nc/4.0/.

\section{REFERENCES}

1. Villalón CM, Olesen J. The role of CGRP in the pathophysiology of migraine and efficacy of CGRP receptor antagonists as acute antimigraine drugs. Pharmacol Ther. 2009;124:309-23.

2. American Headache Society. The American Headache Society position statement on integrating new migraine treatments into clinical practice. Headache. 2019;59:1-18.

3. Sacco S, Bendtsen L, Ashina M, et al. European headache federation guideline on the use of monoclonal antibodies acting on the calcitonin gene related peptide or its receptor for migraine prevention. J Headache Pain. 2019;20:6.

4. Dodick DW, Goadsby PJ, Spierings ELH, Scherer JC, Sweeney SP, Grayzel DS. Safety and efficacy of LY2951742, a monoclonal antibody to calcitonin gene-related peptide, for the prevention of migraine: a phase 2, randomised, double-blind, placebo-controlled study. Lancet Neurol. 2014;13: 885-92.

5. Skljarevski V, Oakes TM, Zhang Q, et al. Effect of different doses of galcanezumab vs placebo for episodic migraine prevention: a randomized clinical trial. JAMA Neurol. 2018;75:187-93.

6. Dodick DW, Ashina M, Brandes JL, et al. ARISE: A Phase 3 randomized trial of erenumab for episodic migraine. Cephalalgia. 2018;38:1026-37.

7. Goadsby PJ, Reuter U, Hallstrom Y, et al. A controlled trial of erenumab for episodic migraine. N Engl J Med. 2017;377:2123-32.

8. Tepper S, Ashina M, Reuter U, et al. Safety and efficacy of erenumab for preventive treatment of chronic migraine: a randomised, double-blind, placebo-controlled phase 2 trial. Lancet Neurol. 2017;16:425-34.

9. Dodick DW, Silberstein SD, Bigal ME, et al. Effect of fremanezumab compared with placebo for prevention of episodic migraine: a randomized clinical trial. JAMA. 2018;319:1999-2008.

10. Silberstein SD, Dodick DW, Bigal ME, et al. Fremanezumab for the preventive treatment of chronic migraine. N Engl J Med. 2017;377:2113-22.

11. Dodick DW, Goadsby PJ, Lucas C, et al. Phase 3 randomized, placebo-controlled study of galcanezumab in patients with chronic cluster headache: results from 3-month double-blind treatment. Cephalalgia. 2020;40:935-48.

12. Goadsby PJ, Dodick DW, Leone M, et al. Trial of galcanezumab in prevention of episodic cluster headache. N Engl J Med. 2019;381:132-41.

13. Silberstein SD, Stauffer VL, Day KA, Lipsius S, Wilson MC. Galcanezumab in episodic migraine: subgroup analyses of efficacy by high versus low frequency of migraine headaches in phase 3 studies (EVOLVE-1 \& EVOLVE-2). J Headache Pain. 2019;20:75.

14. Ashina M, Saper J, Cady R, et al. Eptinezumab in episodic migraine: a randomized, double-blind, placebo-controlled study (PROMISE-1). Cephalalgia. 2020;40:241-54.

15. Lipton RB, Goadsby PJ, Smith J, et al. Efficacy and safety of eptinezumab in patients with chronic migraine: PROMISE-2. Neurology. 2020;94: e1365-77.

16. Detke HC, Goadsby PJ, Wang S, Friedman DI, Selzler KJ, Aurora SK. Galcanezumab in chronic migraine: the randomized, double-blind, placebo- 
controlled REGAIN study. Neurology. 2018;91: e2211-21.

17. Mulleners WM, Kim BK, Láinez MJA, et al. Safety and efficacy of galcanezumab in patients for whom previous migraine preventive medication from two to four categories had failed (CONQUER): a multicentre, randomised, double-blind, placebo-controlled, phase 3b trial. Lancet Neurol. 2020;19: 814-25.

18. Skljarevski V, Matharu M, Millen BA, Ossipov MH, Kim BK, Yang JY. Efficacy and safety of galcanezumab for the prevention of episodic migraine: results of the EVOLVE- 2 phase 3 randomized controlled clinical trial. Cephalalgia. 2018;38:1442-54.

19. Stauffer VL, Dodick DW, Zhang Q, Carter JN, Ailani J, Conley RR. Evaluation of galcanezumab for the prevention of episodic migraine: the EVOLVE-1 randomized clinical trial. JAMA Neurol. 2018;75: 1080-8.

20. Citrome L. Compelling or irrelevant? Using number needed to treat can help decide. Acta Psychiatr Scand. 2008;117:412-9.

21. Citrome L, Ketter TA. When does a difference make a difference? Interpretation of number needed to treat, number needed to harm, and likelihood to be helped or harmed. Int J Clin Pract. 2013;67:407-11.

22. Newcombe RG. Interval estimation for the difference between independent proportions: comparison of eleven methods. Stat Med. 1998;17:873-90.

23. Vo P, Wen S, Martel MJ, Mitsikostas D, Reuter U, Klatt J. Benefit-risk assessment of erenumab and current migraine prophylactic treatments using the likelihood of being helped or harmed. Cephalalgia. 2019;39:608-16.
24. Andrade C. Likelihood of being helped or harmed as a measure of clinical outcomes in psychopharmacology. J Clin Psychiatry. 2017;78:e73-5.

25. Akobeng AK. Communicating the benefits and harms of treatments. Arch Dis Child. 2008;93: $710-3$.

26. Pinson L, Gray GE. Psychopharmacology: number needed to treat: an underused measure of treatment effect. Psychiatr Serv. 2003;54(145-6):154.

27. Straus SE. Individualizing treatment decisions. The likelihood of being helped or harmed. Eval Health Prof. 2002;25:210-24.

28. Dalton GW, Keating JL. Number needed to treat: a statistic relevant for physical therapists. Phys Ther. 2000;80:1214-9.

29. Cook RJ, Sackett DL. The number needed to treat: a clinically useful measure of treatment effect. BMJ. 1995;310:452-4 (Erratum in: BMJ 1995;310:1056).

30. Straus SE, Glasziou P, Richardson WS, Haynes RB. Evidence-based medicine: how to practice and teach EBM. 5th ed. Elsevier; 2018.

31. Sackett DL, Rosenberg WM, Gray JA, Haynes RB, Richardson WS. Evidence based medicine: what it is and what it isn't. BMJ. 1996;13(312):71-2.

32. Schoenen J, Manise M, Nonis R, Gérard P, Timmermans G. Monoclonal antibodies blocking CGRP transmission: an update on their added value in migraine prevention. Revue Neurolog. 2020;176: 788-803.

33. Drellia L, Kokoti L, Deligianni CI, Papadopoulos D, Mitsikostas DD. Anti-CGRP monoclonal antibodies for migraine preventions: a systemic review and likelihood to help or harm analysis. Cephalalgia. 2021;41:851-64. 